\title{
Quality of Life in Hearing Impaired Youth with Amplification System
}

\author{
Seung-Deok Heo \\ Department of Speech-Language Pathology, College of Rehabilitation Science, Daegu University, Gyeongsan, Korea
}

Correspondence: Seung-Deok Heo, PhD Department of Speech-Language Pathology, College of Rehabilitation Science, Daegu University, 201 Daegudae-ro, Jillyang-eup, Gyeongsan 38453, Korea Tel: $+82-53-850-4326$

Fax: $+82-53-850-4329$

E-mail: audiolog@daegu.ac.kr

Received: March 8, 2018

Revised: July 19, 2018

Accepted: July 27, 2018
Objectives: It is possible to compensate for hearing loss with an amplification system. When the hearing loss is compensated for effectively, the quality of life (QOL) of a person with a hearing impairment can be improved. In the interest of this improvement, it is necessary to analyze the $\mathrm{QOL}$ of hearing impaired $(\mathrm{HI})$ individuals who are using an amplifier. This study aims to examine the QOL of HI-youth. Methods: The participants were adult males and females, aged 20- to 29-year-old who were randomly selected through a social network service (SNS). They were classified into two groups: 19 participants who were using a hearing aid and/or cochlear implant, and 46 participants who had no hearing loss. The questionnaire that was used was the World Health Organization Quality of Life Scale Abbreviated Version (WHOQOL-BREF). Response reliability was analyzed with Cronbach's a $(=.923)$, response scores were analyzed with descriptive statistics, and a one-way analysis of variance was used to analyze the relationship between two groups. Results: When the two groups were compared, there was a significant difference in the average response scores regarding physical health according to category of the participants $(p<.05)$. Significant differences were also observed in the sub-domains, including 'hearing loss disturbs mywork' $(p=.000)$,'the hearing aid is needed' $(p=.000)$ (physical domain), 'life is sufficiently meaningful' $(p=.013)$ (psychological domain), 'life security' $(p=.012)$, 'information accessibility' $(p=.010)$, 'satisfaction with local health care service' $(p=.017)$ (environment domain), etc. Conclusion: The responses of HI-youth indicated dissatisfaction in respect to using the amplifier, safety of life, accessibility to information and health care service, and the meaningfulness of life.

Keywords: Quality of life, QOL, Hearing impaired, Cochlear implants, Hearing aids
세계보건기구(World Health Organization, WHO)는 건강을 “질병이 없고 신체적, 정신적, 사회적으로 잘 사는 것”으로 정의하 며, 삶의 질을 "현재의 사회적 가치와 문화적 상황을 고려하여 삶 의 목표와 기대, 기준, 고민 등을 고려한 개인의 인식"으로 각각 정 의 한다(WHO, 2018). 삶의 질은 개인의 신체와 심리적 건강, 신념, 사회적 관계, 주변 환경 등 다양한 문화적 환경 차이에도 불구하고 평가할 필요가 있어서 세계 각국 15 개 센터가 서로 협력하여 도구 를 개발하였다(WHO, 2018). WHO 삶의 질 평가도구는 최근 2 주 동안의 경험을 근거로 다섯 개 척도 중 하나를 선택하는 방식이며, 100 개의 문항으로 개발한 World Health Organization Quality of Life Assessment Instrument (WHOQOL-100) (WHO, 1995, 1997a)
와 26개 문항으로 축약한 World Health Organization Quality of Life Scale Abbreviated Version (WHOQOL-BREF; University of Washington, 2014)을 각각 발표하였고(WHO, 1997b), 비슷한 수준 으로 우수한 신뢰도와 타당도가 있는 우리말 도구도 사용되고 있 다(Min, Kim, \& Park, 2002).

삶의 질 평가는 인간 삶의 영역 전반에서 시도하고 있다. 임산부 의 경우 기관 간 비교가 어려운 점이 있으나(Morin et al., 2017) 배 우자 만족도, 신체적 변화와 활동 제한, 노동 등이 삶의 질에 영향 을 끼친다(Mazúchová, Kelčíková, \& Dubovická, 2018). 갑상샘암 의 경우 피로와 우울로 유방, 직장, 전립샘암보다 삶의 질이 낮으며 (McIntyre, Jacques, Palazzo, Farnell, \& Tolley, 2018), 말·언어장애 
영역에서 말더듬의 경우도 자아, 자신감 등 자기효능감이 낮으면 삶 의 질도 낮아지는 것으로 나타났다(Carter, Breen, Yaruss, \& Beilby, 2017).

청력손실은 인구학적 변화, 산업 발전, 환경적 요인 등으로 증가 하고 있으며, 미국의 경우 두 귀 모두 난청인 경우가 최대 3,000 만 명, 한 귀만 있는 경우가 최대 4,800만 명 정도이다(Martin \& Clark, 2015). 우리나라는 277,431명이 청력손실이 있으며(Ministry of Health and Welfare, 2016), 청력손실을 이유로 장애인 복지법상 장 애로 등록한 난청자는 250,334명이다(Korean Statistical Information Service, 2017). 청력손실로 불편을 겪고 있으나 기준에 들지 않 는 난청자와 등록하지 않는 난청자 등을 포함하면 인구의 $10 \%$ 까지 추산하기도 한다. 청력손실의 심각성은 말.언어 이해에 지장을 주 고, 구어 표현, 문제 해결력, 사고력 같은 상위 언어적 발달 지체, 학 업 성취도 저하, 또래 관계 형성의 문제 등을 야기할 수 있다(Martin \& Clark, 2015).

청년들은 세상의 급격한 변화 속에서 무한한 경쟁을 치르면서 성장해야 하는 힘든 여정에 노출되어 있어서 폭넓은 지적 성취와 충만한 자신감이 요구되는 세상에 살고 있다. 그러나 난청 청년들 은 이미 청소년기부터 청력손실이 없는 또래에 비해 의사소통 자신 감, 자율성, 역할 및 자아, 자존감, 일상생활 참여, 타인과 상호작용 등에서 뒤처져 있다(Choi, Kim, Rha, \& Kim, 2011). 난청자의 삶의 질은 노인의 경우 신체, 심리, 사회적 관계 등 전반적으로 만족을 느 끼지 못하나(Hwang \& Heo, 2016a) 청년들의 경우 신체적 범주에 서(Hwang \& Heo, 2016b), 그리고 듣기 능력 제한에 따른 의사소통 의 한계로(Kim \& Yoon, 2017) 삶의 질이 낮다. 청력손실은 개인 휴 대용 보청기, 이식형 보청기, 청각보조장치 등을 사용하여 보상할 수 있으며, 이들 장치는 난청자의 손상된 감각기관 기능을 대신하 여 의사소통과 삶의 질 개선에 도움을 줄 수 있다(Looi, Lee, \& Loo, 2016; Said, 2017). 이들의 삶의 질 개선은 원인을 근본적으로 분석 하여 효과적인 재활과 합리적인 복지 목표를 설정하는 데 도움이 되고, 이를 체계적으로 접근하여야 개선이 가능하기 때문에 중요 하다. 그러나 이에 대한 체계적 연구가 많지 않다.

이 연구는 증폭기를 사용하고 있는 청년 난청자의 삶의 질을 알 아보는 데 있다.

\section{연구방법}

\section{연구대상}

연구에는 대구·경북지역 대학 이상에 재학 중인 20세부터 29세사 이 81명이참여하였고, 이들은 연구집단과 대조집단으로 나뉘었다.
연구집단은 의료기관 등에서 청력손실을 확진 받고 보청기나 인 공와우를 사용 중인 평균 23.1세 $( \pm 1.76$ 세) 남자 9명, 평균 21.8세 ( \pm 2.44 세) 여자 10 명 등 모두 19 명이었다. 이들 중 1 명은 인공와우 만, 2 명은 보청기만을 사용하였고, 나머지 16 명은 인공와우와 보청 기를 모두 사용하는 bimodal 양이 청취자였다.

대조집단은 청력을 난청선별 지수(hearing handicap inventory, $\mathrm{HHI} ; \mathrm{Heo}, 2017)$ 로 확인하였고, 필요한 경우 스마트폰 기반 순음청 각선별(pure tone screening, PTS; Heo, Park, \& Song, 2017)을 추가 로 확인하였다. $\mathrm{HHI}$ 는 정상 청력 범위가 18 점 미만이지만 선별하 기 어려운 미세(slight) 및 경도(mild) 난청 등을 고려하여 4점 이상 을 배제하였고, 일부 시행한 PTS는 $1,2,3,4 \mathrm{kHz}$ 가청역치가 $25 \mathrm{~dB}$ $\mathrm{HL}$ 이하인 경우로 하였다. 대조집단은 청력손실을 자각하지 않는 62 명이 참여하였으나 $\mathrm{HHI}$ 가 4점에서 10점 사이에 있었던 7명과 HHI 및 WHOQOL-BREF 응답에 일부 누락이 있었던 9명 등 모두 16 명을 제외한 46 명만을 대조집단으로 하였다. 대조집단은 남자가 23 명으로 평균 25.9 세 $( \pm 2.39$ 세)이었고, 여자가 23명으로 평균 24.1 세( \pm 2.1 세 $)$ 이었다.

\section{연구방법}

참여자 선정은 희망자에게 소셜네트워크서비스(social network service, SNS)로 연구 목적과 방법 등을 설명한 후, 이를 충분히 이 해하고 응답과 결과 활용에 동의한 경우로 하였다. 참여자에게는 청력손실 자각 여부를 포함한 전신 건강 상태를 추가로 확인하고, HHI와 WHOQOL-BREF에 응답할 수 있는 인터넷(Google 설문) 주소를 배포하였다. PTS용 앱은 기능과 활용도를 설명하여 별도로 요청한 경우 전송하였고, 결과 화면을 별도로 요청하였다. 회신된 PTS에서 $1,2,3,4 \mathrm{kHz}$ 가청역치가 $25 \mathrm{~dB} \mathrm{HL}$ 이상인 경우는 없었다.

WHOQOL-BREF은 전반적인 만족도와 건강 관련 각각 1 문항 을 시작으로 신체적 건강 관련 7문항, 심리적 건강 관련 6문항, 사회 적 건강 3 문항, 환경 관련 8 문항 등 모두 26 문항이 무순으로 배정되 어 있다.

설문 문항은 'Q1, 삶의 질에 전반적으로 만족 한다', 'Q2, 건강상 태에 전반적으로 만족 한다, 'Q3, 청력손실이 내가 할 일을 방해 한 다, ' $\mathrm{Q} 4$, 일상생활에 보청기가 꼭 필요하다', 'Q5, 삶을 충분히 즐기 고 있다, ‘ $\mathrm{Q} 6$, 내 삶은 충분히 의미가 있다', ‘Q7, 일에 잘 집중할 수 있다, 'Q8, 안전한 삶을 살고 있다', 'Q9, 좋은 주거환경에 살고 있 다, 'Q10, 충분한 에너지를 가지고 있다', 'Q11, 외모에 만족 한다', 'Q12, 경제적으로 여유가 있다', 'Q13, 내게 필요한 정보에 쉽게 접 근할 수 있다, ' $\mathrm{Q} 14$, 충분한 여가 시간이 있다, 'Q15, 신체적으로 왕 성한 활동이 가능하다', 'Q16, 건강한 수면을 즐기고 있다', 'Q17, 현 
재 업무에 만족하고 있다, 'Q18, 업무 수행 능력에 만족하고 있다', 'Q19, 스스로에 대해 만족 한다', 'Q20, 대인관계에 만족 한다', 'Q21, 이성관계에 만족 한다', 'Q22, 친구로부터 만족할만한 도움을 받을 수 있다, 'Q23, 주거환경에 만족 한다, 'Q24, 지역 의료서비스에 만 족 한다', 'Q25, 지역 대중교통에 만족 한다', 'Q26, 슬픔, 절망, 불안, 우울 등 부정적 감정을 느끼고 있다' 등이다.

이들 문항에 대한 참여자의 응답은 전혀 아니다(1점), 약간 그렇 다(2점), 그렇다(3점), 많이 그렇다(4점), 매우 많이 그렇다(5점) 등 으로 할 수 있고, 점수는 응답자가 선택한 점수로 결정하였다. 다만, 부정적 의미를 담은 3 번, 4 번, 26 번 질문은 ' 6 '에서 해당 점수를 뺀

Table 1. Score of World Health Organization Quality of Life Scale Abbreviated Version (WHOQOL-BREF)

\begin{tabular}{|c|c|c|}
\hline Domain & Hearing impaired youth & Normal limits of hearer \\
\hline \multicolumn{3}{|l|}{ Overall 0OL } \\
\hline 01 (G1) & $3.684 \pm .671$ & $3.891 \pm .737$ \\
\hline \multicolumn{3}{|l|}{ Overall health } \\
\hline 02 (G4) & $3.684 \pm .820$ & $3.783 \pm .841$ \\
\hline Physical health & $3.203 \pm .505^{*}$ & $3.887 \pm .523^{*}$ \\
\hline $6-03$ & $3.053 \pm 1.079^{*}$ & $4.739 \pm .855^{*}$ \\
\hline $6-04$ & $2.263 \pm 1.147^{*}$ & $4.870 \pm .653^{*}$ \\
\hline 010 & $3.316 \pm .946$ & $3.348 \pm 1.016$ \\
\hline 015 & $3.632 \pm 1.049$ & $3.822 \pm 1.093$ \\
\hline 016 & $3.474 \pm .905$ & $3.261 \pm .999$ \\
\hline 017 & $3.579 \pm .769$ & $3.630 \pm .799$ \\
\hline 018 & $3.105 \pm .937$ & $3.522 \pm .937$ \\
\hline Psychological health & $3.286 \pm .631$ & $3.573 \pm .664$ \\
\hline 05 & $3.222 \pm .878$ & $3.370 \pm 1.103$ \\
\hline 06 & $3.000 \pm .882^{*}$ & $3.870 \pm 1.046^{*}$ \\
\hline 07 & $3.474 \pm .841$ & $3.609 \pm 1.021$ \\
\hline 011 & $2.833 \pm 1.249$ & $3.109 \pm 1.100$ \\
\hline 019 & $3.579 \pm .607$ & $3.609 \pm .745$ \\
\hline $6-026$ & $3.579 \pm 1.017$ & $3.870 \pm .859$ \\
\hline Social health & $3.491 \pm .489$ & $3.594 \pm .644$ \\
\hline 020 & $3.526 \pm .841$ & $3.674 \pm .762$ \\
\hline 021 & $3.421 \pm .507$ & $3.261 \pm .880$ \\
\hline 022 & $3.526 \pm .612$ & $3.848 \pm .729$ \\
\hline Environmental conditions & $3.223 \pm .431$ & $3.487 \pm .684$ \\
\hline 08 & $3.000 \pm .882^{*}$ & $3.696 \pm .940^{*}$ \\
\hline 09 & $3.368 \pm .761$ & $3.500 \pm 1.130$ \\
\hline 012 & $2.526 \pm .905$ & $2.587 \pm 1.100$ \\
\hline 013 & $2.789 \pm .855^{*}$ & $3.587 \pm 1.066^{*}$ \\
\hline 014 & $2.895 \pm 1.049$ & $3.000 \pm 1.174$ \\
\hline 023 & $3.842 \pm .602$ & $3.622 \pm .984$ \\
\hline 024 & $3.579 \pm .838^{*}$ & $4.065 \pm .680^{*}$ \\
\hline 025 & $3.833 \pm .786$ & $3.826 \pm 1.018$ \\
\hline
\end{tabular}

${ }^{*} p<.05$.
값으로 하였다.

Cronbach's $\alpha$ 로 검증한 응답 신뢰도는 .923로 관찰되었다.

\section{결과의 분석}

연구집단과 및 대조집단의 삶의 질 점수는 신체적 건강, 심리적 건강, 사회적 건강, 환경 조건 등 각 범주와 각 문항별로 기술통계 하였고, 두 집단 사이의 차이는 일원분산분석(One-Way Analysis of Variance)으로 비교하였다(IBM SPSS Statistics version 22).

\section{연구결과}

범주별 삶의 질은 신체적 건강, 심리적 건강, 사회적 건강, 환경 조 건의 순서로 연구집단이 $3.203 \pm .505,3.286 \pm .631,3.491 \pm .489$, $3.223 \pm .431$ 로, 대조집단이 $3.887 \pm .523,3.573 \pm .664,3.594 \pm .644$, $3.487 \pm .684$ 로 각각 관찰되었다(Table 1).

두 집단의 범주별 관계는 신체적 건강 범주에서만 유의한 차이 가 관찰되었고 $(p=.000)$, 심리적 건강 범주 $(p=.113)$, 사회적 건강 범주( $p=.534)$, 환경 조건 범주 $(p=.124)$ 의 경우 유의한 차이가 관 찰되지 않았다(Table 1).

두 집단의 문항별 관계는 신체적 건강 범주에서 '청력손실이 할 일 을 방해 한다' $(p=.000)$, '일상생활에서 보청기가 필요하다' $(p=.000)$ 문항이, 심리적 건강 범주에서 '삶이 충분히 의미 있다' $(p=.013)$ 문 항이, 환경 조건 범주에서 '안전한 삶’ $(p=.012)$, '정보 접근성' $(p=.010)$, '지역 의료서비스 만족도' $(p=.017)$ 문항 등이 각각 유의한 차이를 보였다.

\section{논의 및 결론}

청년 난청자들은 보청기나 인공와우를 통해 환경 및 말소리를 듣는 데 도움(Cohen, Labadie, Dietrich, \& Haynes, 2004)을 받고 있지만 신체적 건강 범주에서 삶의 질은 정상 청력자들 보다 낮게 평가하고 있었다. 문항을 통해 구체적으로 살펴보면, 청년 난청자 들은 정상 청력자들과 마찬가지로 충분한 에너지( $\mathrm{Q} 10)$ 를 가지고, 신체적으로 왕성한 활동(Q15)을 할 수 있으며, 현재 업무(Q17)와 업무 수행 능력(Q18)에 만족하면서 건강한 수면(Q16)을 즐기고 있 는 것으로 응답하였다. 그러나 청력손실이 일을 방해(Q3)하고, 일 상생활에 보청기가 꼭 필요 $(\mathrm{Q} 4)$ 하다는 점에서 신체적 범주의 삶의 질을 낮게 인식하는 것으로 나타났다.

이러한 인식은 이 연구에 참여한 난청 청년 19 명 중 17 명이 인공 와우를 이식받았다는 점을 고려해야 한다. 인공와우 이식은 보청 
기로 도움 받기 어려운 고도 이상의 난청자들이 대상이다. 여기에 환경 소음(Hyun \& Yim, 2013)과 인공와우의 송화기 감도 및 장치 내부 잡음 등의 영향 $(\mathrm{Heo}, 2016)$ 이 더해져서 교정 청력은 여전히 정 상 범위에 이르지 않는 경우가 많다. 물론 이식자들은 삶의 만족 정 도에서 정상 청력자들과 별다른 차이를 느끼지 않기도 하지만(Kim \& Yoon, 2017), 아동 이식자들의 경우 학교생활에서 피로(Looi et al., 2016)를 느끼기도 한다. 이처럼 생활에서 느끼는 한계와 장치 사용에 따른 부담이 신체적 범주의 삶의 질을 낮게 평가한 것으로 추정한다.

청년 난청자들은 정서적 건강 범주에서 적당한 수준의 부정적 감정(Q26)을 느끼지만 자신의 일에 집중(Q7)하고 삶을 즐기면서 (Q5) 외모(Q11)와 자신에게 만족(Q19)하는 것으로 응답하여 정상 청력자들과 마찬가지로 평가하였으나 삶이 충분히 의미(Q6) 있는 가에 대해서는 낮게 평가하였다. 청년 난청자들의 이러한 평가는 행복감을 경제적, 가족적 지원에 의존하고 부정적 기대나 건강이 나쁠수록 낮게 평가하는 청소년들의 성향(Lee, 2015)이 반영된 것 으로 추정된다.

사회적 건강 범주에서는 청년 난청자들이 정상 청력자들과 마찬 가지로 대인관계(Q20) 및 이성관계(Q21)에 만족하고, 친구들로부 터 충분한 도움(Q22)을 받고 있는 것으로 나타났다. 이것은 장애에 대한 사회적 시선 변화를 원인으로 볼 수도 있으나 장애 학생에게 제공되는 복지서비스에 의한 영향인지, 청력손실을 가진 또래 대학 생들과 형성된 유대감에 의한 것인지는 분석할 필요가 있을 것이다.

환경 조건 범주에서는 건강, 주거, 고용, 임금, 가족 공동체 등의 삶이 질이 악화되는(Statistics Korea, 2017) 조건에서도 가정이나 가족 구성원의 지원을 받는 주거 환경(Q9, Q23), 경제적 여유(Q12), 충분한 여가(Q14) 그리고 지역 대중교통 $(\mathrm{Q} 25)$ 등에 대해서 정상 청 력자들과 비슷하게 만족하고 있는 것으로 평가하였다. 그렇지만 안 전(Q8), 필요한 정보 접근성(Q13), 지역 의료서비스(Q24) 측면에서 의 삶의 질을 낮게 평가하였다. 안전이나 정보 접근의 경우 안정적 인 사회 주류 구성원으로서 자아를 실현하기 위해 많은 경쟁을 해 야 하는 시대적 상황(Joung \& Lim, 2014; Song \& Lee, 2017)과 관련 이 있을 것으로 추정되며, 지역 의료서비스의 경우 적극적인 재활 서비스가 필요한 인공와우 이식 및 청각언어재활 과정에서 느낀 지 역 간 격차에 의한 것으로 추정한다.

결론적으로, 증폭장치를 사용하고 있는 청년 난청자들은 범주 별 삶의 질에서 청력손실과 증폭장치 사용에 따른 불편으로 신체 적 건강에 대해 만족도가 낮은 것으로 관찰되었다. 문항별 삶의 질 에서는 청력손실과 증폭기 사용, 삶의 의미, 안전, 필요한 정보 접근 성, 지역 의료서비스 등에서 만족도가 낮은 것으로 관찰되었다.

\section{REFERENCES}

Carter, A., Breen, L., Yaruss, J. S., \& Beilby, J. (2017). Self-efficacy and quality of life in adults who stutter. Journal of Fluency Disorders, 54, 14-23.

Choi, H. Y., Kim, Y. W., Rha, D. W., \& Kim, H. H. (2011). The quality of communication life scale-Korean version. Korean Journal of Communication Disorders, 16, 388-396.

Cohen, S. M., Labadie, R. F., Dietrich, M. S., \& Haynes, D. S. (2004). Quality of life in hearing-impaired adults: the role of cochlear implants and hearing aids. Otolaryngology-Head and Neck Surgery, 131, 413-422.

Heo, S. D. (2016). Audiology: aural rehabilitation with cochlear implant. Seoul: Pakhaksa.

Heo, S. D. (2017). Effectiveness of the Hearing Handicap Inventory for Elderly (HHIE) in measuring the current state of presbycusis. Communication Sciences \& Disorders, 22, 170-176.

Heo, S. D., Park, C. H., \& Song, B. S. (2017). Comparison of smart phone application based hearing screening and hearing handicap Inventory. Journal of Rehabilitation Welfare Engineering \& Assistive Technology, 10, 73-79.

Hwang, S. Y., \& Heo, S. D. (2016a). Influence of presbycusis on quality of life. Proceeding of the 4th International Conference on Korean Speech-Language and Hearing Association and International Conference on Communication Disorders and Related Sciences, Gwangju, Korea, 498-501.

Hwang, S. Y., \& Heo, S. D. (2016b). Quality of life in hearing impaired youth. Proceeding of the 4th International Conference on Korean Speech-Language and Hearing Association and International Conference on Communication Disorders and Related Sciences, Gwangju, Korea, 322-325.

Hyun, S. H., \& Yim, D. (2013). The performance on degraded listening task in children with cochlear implants. Communication Sciences \& Disorders, 18, 86-97.

Joung, S. H., \& Lim, E. J. (2014). A study on the life experiences of employed youth-single households. Financial Planning Review, 7, 1-19.

Kim, D. H., \& Yoon, M. S. (2017). Predicting the quality of communication life of university students with hearing loss. Communication Sciences \& Disorders, 22, 827-836.

Korean Statistical Information Service. (2017). Number of registered-disabilities depending on type and gender. http://kosis.kr/statisticsList/statisticsList_ 01List.jsp?vwcd=MT_ZTITLE\&parmTabId=M_01_01\#SubCont.

Lee, M. S. (2015). The differential influences of health, social-support, and future-expectation on Korean young people's subjective happiness and emotional well-being. Korean Journal of Youth Studies, 22, 179-199. 
Looi, V., Lee, Z. Z., \& Loo, J. H. Y. (2016). Hearing-related quality of life outcomes for Singaporean children using hearing aids or cochlear implants. European Annals of Otorhinolaryngology, Head and Neck Diseases, 133, S25S30.

Martin, F. N., \& Clark, J. G. (2015). Introduction to audiology (12th ed.). Seoul: Pakhaksa.

Mazúchová, L., Kelčíková, S., \& Dubovická, Z. (2018). Measuring women’s quality of life during pregnancy. Kontakt, 20, e31-e36.

McIntyre, C., Jacques, T., Palazzo, F., Farnell, K., \& Tolley, N. (2018). Quality of life in differentiated thyroid cancer. International Journal of Surgery, 50, 133-136.

Min, S. K., Kim, K. I., \& Park, I. H. (2002). Korea version of WHOQOL. Seoul: Hana Medical Publishers.

Ministry of Health and Welfare. (2016). Incidence of major disabilities depending on type and gender. http://kosis.kr/statHtml/statHtml.do?orgId= 117\&tblId=DT_11732S0104\&conn_path=I2.

Morin, M., Vayssiere, C., Claris, O., Irague, F., Mallah, S., Molinier, L., \& Matillon, Y. (2017). Evaluation of the quality of life of pregnant women from 2005 to 2015. European Journal of Obstetrics \& Gynecology and Reproductive Biology, 214, 115-130.

Said, E. A. (2017). Health-related quality of life in elderly hearing aid users vs. non-users. Egyptian Journal of Ear, Nose, Throat and Allied Sciences, 18,
271-279.

Song, D. W., \& Lee, K. (2017). A cultural analysis of the varying modes of survival and the particular structures of feeling among young adults in contemporary South Korea in an era of fierce competition and widespread social uncertainty. Korean Journal of Communication \& Information, 84, 28-98.

Statistics Korea. (2017). Result of composite index of the quality of life. http:// kostat.go.kr/portal/korea/kor_nw/2/1/index.board?bmode=read\&aSeq= 359457.

University of Washington. (2014). WHOQOL-BREF US version (Questionnaire 1997). http://depts.washington.edu/seaqol/docs/WHOQOL-BREF\% 20and\%20Scoring\%20Instructions.pdf.

World Health Organization. (1995). The 100 questions with response scales (WHOQOL-100). http://www.who.int/healthinfo/survey/WHOQOL-100. pdf?ua $=1$.

World Health Organization. (1997a). WHOQOL-BREF. http://www.who. int/healthinfo/survey/WHOQOL_BREF.pdf?ua=1.

World Health Organization. (1997b). WHOQOL-measuring quality of life. http://www.who.int/mental_health/media/68.pdf.

World Health Organization. (2018). Health statistics and information systems WHOQOL: measuring quality of life. http://www.who.int/healthinfo/survey/whoqol-qualityoflife/en/. 


\section{국문초록}

\section{증폭장치 사용 난청 청년의 삶의 질 허승덕}

대구대학교 재활과학대학 언어치료학과

배경 및 목적: 청력손실은 증폭장치로 보상할 수 있으며, 청력손실을 효과적으로 보상하면 난청자(person with hearing impaired, HI) 의삶의 질(quality of life, QOL)도 개선할 수 있다. 이를 위해서는 증폭기를 사용하고 있는 난청자(HI)들의 QOL을 분석할 필요가 있다. 이 연구는 난청 청년(HI_youth)의 QOL을 알아보는 데 있다. 방법: 참가자는 SNS 서비스를 통해 무작위로 선정된 20세부터 29세 사이 의 성인으로 하였다. 이들은 청력손실이 없는 46 명과 보청기나 인공와우를 사용하고 있는 19 명의 두 군으로 구분하였다. 설문은 World Health Organization Quality of Life Scale Abbreviated Version (WHOQOL-BREF)을 사용하였다. 응답은 신뢰도를 분석하였고(Cronbach's $\alpha=.923)$, 두 군 사이 관계는 일원분산 분석하였다. 결과: 두 군 사이에는 신체적 범주에서 유의한 차이가 관찰되었다 $(p<.05)$. 하 위 항목에서 '청력손실이 일을 방해 한다' ( $p=.000)$, ‘보청기가 필요하다' ( $p=.000$ ) (이상 신체적 범주), '삶이 충분히 의미 있다' ( $p=.013)$ (이상 심리적 범주), ‘안전한 삶’ ( $p=.012)$, ‘정보 접근성' $(p=.010)$ ) ‘지역 의료서비스 만족도' $(p=.017$ ) (이상 환경 조건) 등이 유의하였 다. 논의 및 결론: 난청 청년들은 증폭장치 사용, 안전한 삶, 정보 및 의료서비스 접근, 삶의 의미 부분에서 다소 만족스럽지 못한 평가 를 내렸다.

핵심어: 삶의 질, 난청, 인공와우, 보청기

\section{참고문헌}

국가통계포털(2017). 등록장애인수-전국 연도별 장애유형별, 성별. http://kosis.kr/statisticsList/statisticsList_01List.jsp?vwcd=MT_ZTITLE\&par mTabId=M_01_01\#SubCont.

김다혜, 윤미선(2017). 청각장애 대학생의 의사소통 삶의 질 예측변인. 언어청각장애연구, 22, 827-836.

민성길, 김광일, 박일호(2002). 한국판 세계보건기구 삶의 질 척도 지침서. 서울: 하나의학사.

보건복지부 (2016). 주된 장애유형별·성별 재가장애인 출현율. http://kosis.kr/statHtml/statHtml.do?orgId=117\&tblId=DT_11732S0104\&conn_ path=I2.

송동욱, 이기형(2017). 불안정한 현실과 대면하는 이 시대 청년들의 삶에 관한 질적인 분석. 한국언론정보학보, 84, 28-98.

이명숙(2015). 청년세대의 행복감과 정서적 안녕에 미치는 건강, 사회적지지, 삶의 기대요인의 상대적 영향 분석. 청소년학연구, 22, 179-199.

정순희, 임은정(2014). 청년 1인 가구의 삶에 대한 연구. 한국FP학회지, 7, 1-19.

최혜윤, 김용욱, 나동욱, 김향희(2011). ASHA 의사소통 삶의 질 척도의 한국어판 번안: 청소년용. 언어청각장애연구, 16, 388-396.

통계청(2017). 국민 삶의 질 종합지수 작성결과. http://kostat.go.kr/portal/korea/kor_nw/2/1/index.board?bmode = read\&aSeq=359457.

허승덕(2016). 청각학: 인공와우재활. 서울: 박학사.

허승덕(2017). Hearing Handicap Inventory for Elderly (HHIE)로 확인한 노인성 난청 실태. 언어청각장애연구, 22, 170-176.

허승덕, 박찬호, 송병섭(2017). 스마트 폰 애플리케이션 기반 청각선별과 설문 청각선별의 비교. 재활복지공학회논문지, 11, 73-79.

현승희, 임동선(2013). 인공와우이식 아동의 문맥조건에 따른 소음상황듣기 수행능력. 언어청각장애연구, 18, 86-97.

Frederick N. Martin, John Greer Clark (2015). 청각학개론 12판(허승덕 역). 서울: 박학사. 